\title{
PEOPLE AND THEIR PETS IN THE TIMES OF THE COVID-19 PANDEMIC
}

\author{
AVIVA VINCENT ${ }^{1}$, HANNA MAMZER ${ }^{2}$, ZENITHSON NG ${ }^{3}$, \& KATHLEEN J. FARKAS ${ }^{4}$ \\ ${ }^{1}$ Corresponding author: Case Western Reserve University, Mandel School of Applied Social Sci- \\ ence, 11235 Bellflower Road, Cleveland, Ohio, 44106, USA. ORCID: 0000-0003-2527-940X, Email: \\ aviva.vincent@case.edu \\ ${ }^{2}$ Adam Mickiewicz University in Poznań, Szamarzewskiego 89 C, 60-568 Poznań, Poland. ORCID: 0000- \\ 0002-2251-7639,Email:_mamzer@amu.edu.pl \\ ${ }^{3}$ The University of Tennessee, Institute of Agriculture, College of Veterinary Medicine, Department of \\ Small Animal Clinical Sciences, 2407 River Drive, Knoxville, TN 37996. USA. ORCID: 0000-0003-1558- \\ 2683, Email: zng@utk.edu \\ ${ }^{4}$ Case Western Reserve University, Mandel School of Applied Social Science, 11235 Bellflower Road, \\ Cleveland, Ohio, 44106, USA. ORCID: 0000-0002-1937-3603, Email: Kathleen.farkas@case.edu
}

\begin{abstract}
In the face of a global pandemic, domesticated and companion animals are relegated to the most vulnerable stratification of society. Companion animals (pets) have been established as family members in a wide breath of cultures globally; thereby ensuring reliance on humans for maintaining care and wellbeing. Furthermore, those on social media are sharing animal stories, photos, memes, and videos as a mechanism of distraction, enjoyment, and humor. Animals are becoming the force to bring humanity together through crisis, and yet, they require human care and compassion. Amidst the COVID-19 pandemic, the world was confronted with three pertinent questions: 1 . How do individuals provide physical and emotional care and enrichment for pets during a pandemic? 2. Are there zoonotic concerns in caring for a pet? 3. What are the mid- and long-term repercussions of the pandemic for pet care? To address these questions, this paper identifies avenues of support, and challenges that can be addressed in the midst of the pandemic to advance and ensure companion
\end{abstract}


animal welfare. This is the moment we collectively challenge the notion of companion animals as family members and the importance of these very animals in our lives. KEYWORDS: COVID-19, pets, zoonosis, animal welfare, veterinary social work

\section{INTRODUCTION}

On March 11, 2020, the World Health Organization declared COVID-19 a world-wide pandemic (World Health Organization, 2020); which has created situations that are unprecedented in the past 100 years. Situations of psychological crisis are defined as ones that force change of previous behaviour as old patterns become inadequate for reality and its requirements. In the face of pandemics, priorities get redefined. Self-preservation instinct dictates behaviour aimed at individual welfare. In such situations the weakest social categories are mostly exposed to danger and they are most vulnerable. Representatives of these categories have either limited or no means to protect themselves, therefore their susceptibility to harm and injury is the highest. All humans are vulnerable to the novel corona virus, making its spread a universal and global concern. About a month later, the novelty of life with COVID-19 still clings to the corners of daily life. As of this writing, the central directions for dealing with the virus and the disease COVID-19 include social distancing, staying at home, washing your hand and practicing good mental and physical health habits. Routines of work and recreation have all but ceased as people try to comply with the public health guidance. The international community has begun to settle into a routine of social distancing and working from home - with millions of pets by our collective sides.

In western cultures of the $21^{\text {st }}$ century, domesticated animals are arguably the weakest social stratification. As non-linguistic, sentient beings, they have minimal opportunities to protect their own interests. In the current anthropocentrically dominated world animals depend on people. As Donaldson and Kymlicka state in Zoopolis (2011) non-human animals should be treated as citizens of human societies because they have been included by people against their will. This becomes particularly apparent in situations of crisis which usually lead to depletion of resources, thus resulting in shortages. Pets are more than companions, they are family. Yet, they cannot help pay the bills nor can they resource their own food from inside the shared home - especially during a shelter-in-place order.

The Center for Disease Control issued a statement early on that pets are not susceptible to COVID-19. Though there are a number of strains, the specific virus that is wreaking havoc on people does not "jump" to, nor from domesticated pets (Center for Disease Control and Prevention 2020). Herein is the prime situation for animal bonding - people are turning to pets in the home and social media for catharsis that people cannot get from typical social interactions at this time. With daily life moving indoors, people are taking to social media as a communication tool. Social media posts about animals in natural habitats, and not so natural habitats abound as a mechanism of detaching from stress and finding enjoyment in others. Species that adapted to noc- 
turnal behaviours to accommodate human cycle have become more visible in cities as they return to their natural preferences (Forbes 2020; Podlaskie 2020). In Italy, people were so thrilled to see the positive impact of their home-stay that a photo of dolphins in the canals of Venice were hard not to believe (National Geographic, 2020). Though false and exaggerated stories abound, there is plentiful truth and hope to be found as well. Animals on social media are evoking happiness, humor, and compassion: therapy dogs visiting nursing homes through windows (Today 2020) and supporting emergency room doctors (CNN 2020), to parrots demonstrating behaviors that make people laugh (YouTube 2016).

In the United States, many communities have found that the mandatory shelter-inplace has created a pseudo-parental-leave situation, affording time to welcome a new family member into the home. Move over toilet paper, make room for adoptions and fosters! As shelters began to see an influx of surrendered pets, economic hardship, and inability to maintain staffing due to place sanitary conditions and shelter-in-orders, people heeded the call to action and opened their homes to fosters and adoptions (Maddie's Fund 2020). Animal protection societies and shelters have reported simultaneous increases of relinquished and abandoned animals, and applications for foster care after the start of the pandemic in the United States (Localsyr.com 2020). Shelters have reported $100 \%$ increase in foster home applications, while other shelters have seen record adoptions (ASI 2020).

The way humans choose to engage and interact with each other, and with our pets in times of crises demonstrates our dedication to humanity. Innately, humans seek to support each other, find comfort in shared moments, and demonstrate acts of compassion. As people social distance from each other, companion animals/pets become core support systems for physical and emotional wellbeing.

\section{CONCERNS OF PEOPLE WITH PETS}

Companion animals are generally thought to enrich the lives of humans- regardless of what is happening around them. Living with animals and including them in daily routines is linked with various benefits: social interaction, exercise, emotional supports and social connectedness. Chandler (2019) outlines eight domains of pet-owner wellness: emotional and physical nurturance, sense of family, sense of responsibility and purpose, friendship/companionship, social interaction and connections, personal values/spiritual values; fun and play and physical health. Each of these eight dimensions would be affected by the risks presented by the Coronavirus and COVID-19, by social distancing and social isolation responses and the social and economic disruptions associated with the pandemic. Pets react to changes in their social environment and to the emotional state of their humans.

Wood, Martin, Christian, Nathan et al. (2015) studied the impact of pet ownership on social networks and social relationships. Pet owners reported they were able to interact more readily with others in their neighborhoods and that these interactions resulted in supportive relationships and new friendships. Their conclusion was that pet ownership might result in higher levels of social interaction and healthier neigh- 
borhoods. Strong social, neighborhood networks could provide added support and tangible resources to those coping with the limitations of shelter-in-place orders as well as those who are more vulnerable because of age or health conditions.

While the COVID-19 pandemic is unique, past disasters have raised concerns provide some insight about the welfare of companion animals during times of crisis. First responders during Hurricane Katrina quickly learned that rescue efforts had to include pets when many people refused to leave their pets behind; quickly endangering their lives and the lives of others (Zeitlin 2019). Disaster planning experts have since recognized that companion animals must be included in disaster planning and have issued preparedness advice (Federal Emergency Management Agency 2019; Chadwin 2017) Though COVID-19 is not a natural disaster, there is an imperative need for public health guidance inclusive of implications for companion animals and the humans with whom they live.

\section{DISEASE SUSCEPTIBILITY AS A ZOONOTIC DISEASE}

One of the first concerns to emerge with Coronavirus and COVID-19 was about the susceptibility of pets, and the likelihood that the disease could be spread by human-animal contact (Goumenou, Spandidos and Tsatsakis 2020). Although there is some suspicion that COVID-19 originated from bats (Millán-Oñate et al.2020), and is therefore considered a zoonotic disease, infectious disease experts and multiple international and domestic human and animal health organizations do not believe that companion animals can spread COVID-19 to other animals or people at this time (AVMA 2020). At the time of this publication, two dogs (Hong Kong) and one cat (Belgium) that were in contact with COVID-19 infected humans have been reported to test positive for COVID-19. It is likely that these animals were contaminated with the virus, and while this indicates that dogs and cats can become infected, it is unlikely that the virus leads to clinical signs or propagates enough virus to lead to transmission (AVMA 2020).

Additionally, porous surfaces such as pet fur may not transmit the virus as easily as nonporous smooth surfaces (AVMA 2020). Idexx, a veterinary diagnostic laboratory, is currently developing a veterinary-specific COVID-19 PCR test. To date, over 4,000 animals from areas with COVID-19 positive humans have been screened, and all results have been negative (Idexx 2020). Interestingly, the conversation was focused immediately on whether people could contract the virus from their pets, not whether people could give the virus to their pets.

While there is no current evidence that companion animals succumb to clinical disease from COVID-19 or transmit it onto others, further research is warranted and ongoing. Until more information is known about COVID-19 in companion animals, it is prudent to minimize the risk of spread. Prevention of spread of COVID-19 is no different from the precautions that are taken with any other zoonotic disease, with the most critical practice being rigorous handwashing. In addition, the mandate of social distancing during a pandemic is important. Dogs should keep distance from other dogs and people and should not be exposed to high density areas such as dog parks and daycare facilities. Extensive travel with pets should be significantly limited to 
minimize transmission (Anderson, Stull and Weese 2019). These hygiene and preventive practices are especially important for both for pets who are immunocompromised and pet owners who are immunocompromised (Grant and Olsen 1999).

\section{ECONOMIC AND CARE BURDEN}

The extent of the economic impact of Coronavirus and COVID-19 is yet to be determined, but many people have lost their jobs and income as a result of efforts to "flatten the curve" by shutting down all but essential businesses (Oliver 2020; Specktor 2020). For some the added costs of caring for an animal during economic hardship may lead to relinquishing the animal at a shelter. The uncertainly about the fate of the economy and the financial concerns may outweigh the relationship and bond between some humans and their companion animals. For others, daily routines of care, rather than the expense of the animal during times of social-quarantine or social isolation prove to be too great a burden and result in relinquishing the animal to a shelter.

\section{CHANGE IN ROUTINES}

Shelter-in-place orders have altered the daily routines for most United States residents. For many, these orders mean more time to be with their pets and to enjoy interactions with them. There may be more opportunities for walking and playing outside using appropriate social distancing behaviors. Overall, there is likely increased contact during the day.

After the Spanish government-imposed restrictions on leaving the home, Spanish social media humorously suggested walking a plush stuffed dog on a leash was in accordance with the rules: "You can walk a dog. Any dog" (Daily Mail 2020). Humour aside, those who are quarantined and cannot not leave the home may need to explore opportunities to re-train their pets, predominantly dogs and indoor/outdoor cats, to relieve themselves in a designated inside location (Lowrey 2020). This alteration in routine and impromptu training will no doubt be confusing for both person and pet. Working from home also brings changes in the ways in which people and pets interact. Pets do not understand the need to stay away, or stay quiet during conference calls or virtual meetings. However, the occasional cat across the screen, or arm bump by a dog is a nod towards silver linings and an opportunity for humor as people reconnect in this new context.

Compassionate humans will devote adequate time to their companion animals to compensate for the work-related separations. Pets and people experience boredom when experiencing diminished stimulation. Domesticated dogs and cats require stimulation of play to alleviate boredom and stress associated with social isolation and/ or quarantine (Lowrey 2020); since people benefit from play as well, it is mutually beneficial to carve out daily time to engage. A similar attempt to address the needs of animals, specifically their need for play and enrichment, is changing their physical environments. At the Shed Aquarium, caretakers allowed the penguins to wander the grounds of the oceanarium in the absence of visitors (CBS News 2020). Revisiting the 
pull towards social media, zoos around the world have been livestreaming animal play, new births, and lunch-time musings.

\section{VULNERABLE GROUPS}

Older people and those with underlying chronic illness have been deemed more vulnerable for COVID-19 than others. These vulnerable groups may need additional supports to shop for food and supplies for their pet. They may also need communication (e.g. reminders) or physical support to walk and play with their pet(s).

For immunocompromised persons living with pets during a pandemic, the goal is to keep the person with his or her pet in a healthy and mutually beneficial relationship that presents minimal risk to both human and animal. Non-profit programs called human animal support services exist to provide financial, emotional, educational, and practical assistance to disabled or immunocompromised pet owners (Gorczyca, Fine \& Spain 2006). Routine pet ownership practices that immunocompromised people may not be able to safely carry out such as walking, grooming, scooping litter boxes, and administering medications are provided daily by volunteers. However, it is important that volunteers that enter these homes follow appropriate protocols such as social distancing and hand washing to not put themselves or the people who are serve at risk.

Communities with pet owners are working collaboratively through neighbourhood initiatives to walk the dogs for those who are in quarantine (Metro 2020). Using drones for dog walking is among new, possible suggestions on how to tackle the challenge of quarantine with a pet who routinely accesses outside spaces (TurnTo23 2020). Training is still required, as are measures for safety, but it is a creative solution to a current world-wide challenge. Dogs needs to get outside have been met by allowing them outside through windows and balconies. However, stories of physically lowering dogs by a leash from a second-floor balcony seems far less safe as such actions may seriously endanger animals' health and welfare (NY Post 2020).

The risk of becoming ill with COVID-19 and having to be hospitalized can create additional stressors on homeless people with pets. Any single person with a companion animal will experience added stress unless there is a clear plan for the animal's care in the face of extended illness and/or hospitalization. The Humane Society (2020) offers resources for homes with pets, opportunities to foster/adopt, and preparedness plans in the event of illness.

People who experience homeless have been shown to have strong bonds with their companion animals, but the presence of the animal can limit access to shelter services as well as to deter any help if there is a fear the animal will be taken away (Cleary et al. 2019). The human service and animal welfare communities have responded to the need for guidelines, resources, and support by quickly developing and sharing resources for keeping humans and animals together in wellness. My Dog is My Home (2020) and the Co-Sheltering Collaborative (2020) have put forth guidelines for helping individuals facing homelessness, and individuals serving those who are experiencing homelessness, stay with their pets. 


\section{ANIMALS ASSIST IN TIMES OF CRISIS}

Companion animals provide comfort at all times and especially during times of crisis. It is the unconditional support of animals that many cite as the primary ingredient for the success of animal assisted interventions and animal assisted programs. Research has shown that companion animals provide emotional support for adults with mental health challenges (Brooks et al. 2018), for adolescents (Jones, Rice \& Cotton 2019), and for older adults (Bibbo, Curl \& Johnson 2019). Human-animal interaction is beneficial and desired by immunocompromised individuals, but certainly not at the risk of their own physical health (Chan \& Rico 2019). Therefore, any animal-assisted intervention programs should be ceased during pandemics.

However, it stands to reason that pets will be a source of support during the pandemic and during the many societal and economic changes to follow. Animals have been introduced to crisis work by way of crisis response teams. These human-animal teams provide additional resources to clergy, social workers, and other health care professionals reaching out to people affected by crisis (Greenbaum 2006). In addition to the more common collaborations in psychotherapy, animals will be vital collaborators for supporting human-wellbeing as society seeks to alleviate the burdens of the effects of this pandemic.

\section{CONCERNS FOR THE WELLBEING OF PETS}

One construct to ensuring animal welfare, even during a pandemic, is to ensure the five freedoms: the freedom from hunger and thirst; freedom from discomfort; freedom from pain, injury or disease; freedom to express normal behavior; and freedom from fear and distress (FAWC 2009). To attain freedom from pain, injury, and disease, proper veterinary care is essential. Veterinarians are on the front-line to ensure the health and wellbeing of both pets and animals.

\section{PROVIDING VETERINARY CARE}

During a pandemic, it can be challenging to maintain the physical health and wellbeing of companion animals, especially when other life needs may need to be prioritized. Veterinary hospitals are considered essential businesses for emergency care for animals. Veterinarians receive regular guidance from organizations such as the American Veterinary Medical Association on how to operate during these times of uncertainty (AVMA 2020).

However, veterinary hospitals may struggle to remain open as they are faced with the same, if not more risks and challenges as the general public. Veterinary staff may be at increased risk of exposure because of the close contact that is often required between veterinary staff and clients. Additionally, animal patients may be vectors of zoonotic disease transmission, although there is no evidence that domestic animals can transmit COVID-19 to other people or animals at this time. There is evidence that veterinary staff employees may not be as diligent with zoonotic disease prevention under normal circumstances (Wright et al. 2008). These added risks may result in re- 
duced staffing, as employees can elect self-quarantine and choose not to work during these periods. In addition, hospital supplies such as medications and personal protective equipment may be on short supply during these times, as they may not be aware. These factors, coupled with a decreased caseload, make it difficult for veterinary hospitals to safely remain open and profitable.

Veterinary caseloads should be limited to emergencies only with limited direct contact between the veterinary team and the pet owner. If the animal is due for an annual wellness examination or other elective procedure, this may be delayed. Depending on the life stage of the animal (Bartges et al. 2012; Vogt et al. 2010), it is unlikely that a delayed visit to the veterinarian for preventive care will negatively affect the health of the animal. Under most circumstances, adult animals that are overdue for vaccinations should not pose an issue (Ford et al. 2017; Scherk et al. 2013). However, animals that are either very young or very old may be considered immunocompromised, and it is important that these animals receive appropriate attention and vaccinations as advised by their veterinarians. One of the most important preventive measures pet owners can take in preventing infectious disease in their pets is maintaining appropriate social distance.

As pet owners spend more time at home during the times of social distancing, they may notice abnormalities in their pets that are typically not observed because they are not together as frequently. Subtle abnormalities or behavior changes may be more apparent and cause a pet owner to contemplate whether or not this is considered a true emergency to warrant physically going to the veterinarian.

For these types of issues, veterinarians are making telehealth more readily available to clients (Roca and McCarthy 2019). While the consultation does not take the place of a formal face-to-face physical examination, the veterinarian may determine he or she has enough virtual information to make a proper assessment and recommend an appropriate treatment plan. This method may alleviate much stress for the pet owner who is unable to physically go to the veterinary hospital. However, an appropriate veterinarian-client-patient relationship must be established according to state and federal guidelines prior to a formal telemedicine consultation. This stipulation underscores the need for all animals to receive regular preventive veterinary care with a licensed veterinarian prior to a pandemic.

Pets suffering from chronic disease are at risk of not receiving the care they need during a pandemic. These animals often require frequent recheck appointments for assessments, diagnostic tests, treatments, and prescription refills. Telehealth is readily available to meet the needs for assessments, especially since veterinarians have a pre-existing relationship with the pet. However, diagnostic tests and treatments require the animal to be present in the veterinary hospital. Collection of samples for diagnostic testing and routine treatments such as rehabilitation, bandage changes, and wound management that must be done in the hospital setting by veterinary professionals may be permitted on a case by case basis. Prescription medications may be filled using electronic prescribing through a local or remote pharmacy. It is critical that pet owners understand the indications for prescription medications, the consequences of not having the medication, and what to do in the event that a prescription 
is unable to be filled in time. Proper knowledge and consultation with the veterinarian may lead to improved planning to prevent these instances from occurring.

\section{PALLIATIVE CARE AND HUMANE EUTHANASIA}

A significant emotional challenge in providing high quality veterinary care during a pandemic is caring for animals requiring hospice and palliative care and for those that are subject to humane euthanasia. End of life care and euthanasia require a great deal of attention from the veterinary team to both the animal as well as the pet owner. This can be a challenge with limited resources, limited time, and barriers to physical contact where social distancing is mandated. In addition, pet owners are already in a heighted emotional state due to the circumstances of a pandemic, which may exacerbate the emotions processed when contemplating the decision of euthanasia and processing the grief from the loss of a pet (Bishop et al. 2016). While the assessment of quality of life for the animal and discussion of euthanasia may be conducted remotely between veterinarian and pet owner via telemedicine, the physical act of euthanasia requires direct contact (Underwood and Anthony 2013).

The grace of euthanasia relies on a bonded veterinary-client-patient relationship, as the growing majority of pet owners elect to be present during a euthanasia (Dickinson, Roof and Roof 2011). The most ideal circumstance would be for the euthanasia to be conducted in the home setting, but this may be an unrealistic practice during a pandemic. Therefore, if a euthanasia is warranted and the pet owner wishes to be present, advanced planning is required to ensure the process runs as smoothly as possible to minimize the risk of transmission of infectious disease. The International Association for Animal Hospice and Palliative Care (2020) has released practice guidelines for veterinary services that are transparent for clients. Social distancing, the lack of direct contact, overzealous disinfection practices, and uniforms of personal protective equipment worn by the veterinary staff can create a cold and impersonal euthanasia experience. Thus, conversations that explain procedures offer transparency in this highly emotional time. The pet owner needs to understand that these practices are in place to guarantee the safety for all participants. Employing a veterinary social worker or other mental health professional to coordinate and be present for the euthanasia may improve the experience for the grieving pet owner.

\section{REPERCUSSIONS OF THE PANDEMIC FOR COMPANION ANIMAL CARE}

Living in the state of pandemic creates an unavoidable realization that caring for a pet quickly becomes a challenge. For people who have a lower threshold of psychological resistance, or for those who have a lower level of empathy, the instinctive, psychological response may be to reduce stress in their life. In pet ownership, addressing stress in this manner may look like surrendering a pet to a shelter, or relinquishing a pet to a veterinary clinic requesting euthanasia (Vice 2020). Pet who belong to people without appropriate financial means may be abandoned; either by the notion that they have better odds to find food and resources out of the horse, or that the person cannot lon- 
ger serve as a caretaker. This solution is sometimes consciously used by people who do not want to kill an animal, but cannot conceive keeping them either. Being helpless, animals experience the deception of abandonment in a place from which it cannot return home (Mondelli et. al. 2004; Dog Population Management 2011). The current pandemic has raised international concerns of a higher probability of euthanasia of animals in zoological gardens (BBC 2020), and animal shelters (Independent 2020).

When confronting a major crisis, people tend to follow the basic instinct to preserve their genes, concentrate on satisfying their own needs and the needs of their nearest kin. Thereafter, people look to the community around them. The fundamental question arises here - which category do pets belong to? And, what about non-domesticated animals?

While some pets are treated as family members, other animals are kept by people in environments where care and enrichment is delegated. The needs of animals kept for entertainment, for example in zoos, become of lesser importance. History has demonstrated that this stratification of animals can result in tragic situations of killing zoo animals (Baratay, Hardoui \& Fugier 2004; Prenger 2018). Discussions regarding the treatment of livestock and farming animals has been far removed from the conversation about animal welfare and COVID-19. In large part, this is due to the belief that animals for slaughter are not as deserving of care and compassion as those in the home.

Of the same notion, as consumers of meat products, humans are remiss not to consider livestock treatment. In essence COVID-19 may be an iteration of history will be repeating prior health crises (e.g. H5N1/avian flu, Creutzfeldt-Jakob Disease/Mad Cow Disease, and SARS-CoV). The COVID-19 virus is strongly postulated to have originated from animals, and was transmitted to humans by consuming meat and animal products. Tilocca et. al (2020) found that previous contact with the virus may provide a partial/basal immunization that shields humans against circulating COVID-19.

It would be advisable not to blame animals for the outbreak of the epidemic. After all, it has been human activity that led to catastrophic consequences. "Wet markets", which provide minimal space for a variety of species with no veterinary supervision, pose a robust sanitary threat. As noted by the prior zoonotic outbreaks, it is often the unnatural consumption of animals that instigate health crises. The relationship of the present health crisis is illustrated by an internet meme, in which "carnivorous" and "coronavirus" (i.e. COVID-19) is an anagram (PETA 2020). While the actual cause of COVID-19 has not formally been stated, the relationship between people and pets, as well as people with non-domesticated animals is truly the central conversation.

Any individual interested in finding a cure and treatment for COVID-19 would be remiss not to account for the animals serving humans in the medical field. The medical community utilizes "animal models" to test potential antidotes; a technical term for live animals to simulate human genome. strives to create a treatment for COVID-19. Thus, it is not an ideal time to be a lab mouse, unless martyrdom is of interest. The current use of animal models is imperative to the health and wellness of humankind, and yet, we too must recognize the value of animals serving humans to ensure this pandemic shall pass (Sentient 2020). 


\section{CONCLUSION}

For some animals this pandemic may be the opportunity to be adopted (NY Times 2020), while other animals may be less fortunate and may not survive the pandemic with their family intact. More importantly, people must prioritize domesticated animals as family and ensure that, to the best of our collective ability, their needs are met. For the majority of animals increased presence of people at homes is a major, positive environmental shift, particularly for those (especially dogs) who will normally stay in the house alone, while their carers go to work.

The impact of the COVID-19 pandemic will not be known for some time. As Dr. Amy Acton of Ohio said, "We will be looking back at this for years and years. There will be history books written; this truly is that once-in-a-generation, every-hundred-year experience, and we're going to learn so much as a country" (News5 Cleveland 2020); and world-wide. Our companionship with animals has survived thousands of years, and several pandemics. We will move through this together.

FUNDING: This research received no external funding.

CONFLICT OF INTEREST: The authors declare no conflict of interest.

\section{REFERENCES}

Anderson, M. E. C., J. W. Stull and J. S. Weese. 2019. “Impact of Dog Transport on HighRisk Infectious Diseases.” Veterinary Clinics of North America-Small Animal Practice 49(4):615-+. doi: 10.1016/j.cvsm.2019.02.004.

AVMA. 2020, "Covid-19: What Veterinarians Need to Know": AVMA. Retrieved Mar 30, 2020 (https://www.avma.org/sites/default/files/2020-03/COVID-19-What-veterinarians-need-to-know_031520.pdf).

Baratay E., Hardouin-Fugier E. 2004. Zoo: A History of Zoological Gardens in the West. Reaktion Books.

Bartges, Joe, Beth Boynton, Amy Hoyumpa Vogt, Eliza Krauter, Ken Lambrecht, Ron Svec, and Steve Thompson. 2012. "AAHA canine life stage guidelines." Journal of the American Animal Hospital Association 48(1):1-11.

BBC 2020. "Coronavirus: Zoo animals 'under threat' from panic buying" Retrieved on March 26, 2020 (https://www.bbc.com/news/uk-england-somerset-51972533)

Bibbo, Jessica, Angela L. Curl, and Rebecca A. Johnson 2019. "Pets in the Lives of Older Adults: A life course perspective”. Anthrozoos. 32(4):541-554.

Bishop, G., K. Cooney, S. Cox, R. Downing, K. Mitchener, A. Shanan, N. Soares, B. Stevens and T. Wynn. 2016. “2016 Aaha/Iaahpc End-of-Life Care Guidelines.” Journal of the American Animal Hospital Association. 52(6):341-56. doi: 10.5326/Jaaha-Ms-6637. 
Brooks, Helen Louise, Kelly Rushton, Karina Lovell, Penny Bee, Lauren Walker, Laura Grant, and Anne Rogers 2018. "The power of support from companion animals for people living with mental health problems: a systematic review and narrative synthesis of the evidence”. BMC Psychiatry.18:31 DOI 10.1186/s12888-018-16132

CBS News 2020. "Penguine in the Chicago Shedd Aquarium, Closed of Corona Virus fears”. Retrieved on March 26,2020 (https://www.cbsnews.com/news/penguins-chicago-shedd-aquarium-closed-over-coronavirus-fears/)

Center for Disease Control 2020. “Daily Life \& Coping”. Retrieved on March 30, 2020. (https://www.cdc.gov/coronavirus/2019-ncov/daily-life-coping/animals.html?CDC_AA_refVal=https\%3A\%2F\%2Fwww.cdc.gov\%2Fcoronavirus\%2F2019-ncov\%2Fprepare\%2Fanimals.html)

Center for Disease Control and Prevention (2020). If you have animals. Retrieved on March 30, 2020 (https:/www.cdc.gov/coronavirus/2019-ncov/daily-life-coping/ animals.html?CDC_AA_refVal=https\%3A\%2F\%2Fwww.cdc.gov\%2Fcoronavirus\%2F2019-ncov\%2Fprepare\%2Fanimals.html).

Chadwin, Robin. 2017. Evacuation of Pets During Disasters: A Public Health Intervention to Increase Resilience. American Journal of Public Health. 107:1413-1417. doi: 10.2105/AJPH.2017.303877)

Chandler, Cynthis 2019. “Eight Domains of Pet-Owner Wellness: Implications for counselors and counselor training”. In Clinician's guide to treating companion animal issues: Addressing human-animal interaction. Kogan, Lori, (Ed); Blazina, Christopher, (Ed); pp. 103-114; San Diego, CA, US: Elsevier Academic Press.

Cleary, Michelle, Denis Visentin, Deependra Kaji Thapa, Sancia West, Toby Raeburn, and Rachel Kornhaber 2019. “The Homeless and Their Animal Companions: An Integrative Review. Administration and Policy in Mental Health and Mental Health Services Research". Administration and Policy in Mental Health and Mental Health Services Research. 47:47-59 https://doi.org/10.1007/s10488-019-00967-6

CNN 2020. "A service dog in training brings comfort to ER doctors on the frontlines" Retrieved on March 31, 2020 (https://www.cnn.com/2020/03/26/health/therapydog-er-doctor-trnd-wellness/index.html)

Co-Sheltering Collabortive 2020. "COVID-19 Guidelines for Co-Sheltering Environments” Retrieved on March 31, 2020. (https://www.co-shelteringcollaborative. org/covid-19-guidelines)

Daily Mail 2020. “Cops confront man using a TOY dog on a leash to try and cheat Spain's state of emergency quarantine laws that allows pet owners outside to walk their animals" Retrieved on March 26th, 2020 (https://www.dailymail. co.uk/news/article-8126695/Man-defies-Spains-state-emergency-tries-foolpolice-trying-walk-toy-dog.html)

Dickinson, George E., Paul D. Roof, and Karin W. Roof. 2011. "A Survey of Veterinarians in the Us: Euthanasia and Other End-of-Life Issues." Anthrozoos 24(2):167-74. doi: $10.2752 / 175303711 \times 12998632257666$.

Dog Population Management. 2011. FAO/WSPA/IZSAM expert meeting, Banna, Italy 14-19 March 2011. 
Donaldson, Sue, and Will Kymlicka. 2011. Zoopolis: A political theory of animal rights. Oxford University Press.

FAWC. 2009, "Farm Animal Welfare Council - 5 Freedoms”. Retrieved on March 26, 2020. (www.fawc.org.uk/freedoms.htm)

Federal Emergency Management Agency 2019. “Pet Preparedness Checklist”. Retrieved on March 31, 2020 (https://www.fema.gov/media-library/assets/images/166991)

Forbes 2020. "Animals Roam Freely In Italian Cities With Humans In Lockdown" Retrieved on March 26th, 2020 (https://www.forbes.com/sites/davidbressan/2020/03/20/animals-roam-freely-in-italian-cities-with-humans-in-lockdown/\#3526b8cd7956)

Ford, Richard B., Laurie J. Larson, Kent D. McClure, Ronald D. Schultz, and Link V. Welborn. 2017. "2017 AAHA canine vaccination guidelines.” Journal of the American Animal Hospital Association 53(5): 243-251. doi: Doi 10.5326/Jaaha-Ms-6741.

Gorczyca, Kenneth, Aubrey H Fine and C Victor Spain. 2006. “History, Theory, and Development of Human-Animal Support Services for People with Aids and Other Chronic Terminal Illnesses.” Pp. 253-302 in Handbook on Animal-Assisted Therapy: Elsevier.

Goumenou, Marina, Demetrios A Spandidos and Aristidis Tsatsakis. 2020. "Possibility of Transmission through Dogs Being a Contributing Factor to the Extreme Covid-19 Outbreak in North Italy.” Molecular Medicine Reports. doi: 10.3892/ mmr.2020.11037.

Grant, S. and C. W. Olsen. 1999. "Preventing Zoonotic Diseases in Immunocompromised Persons: The Role of Physicians and Veterinarians.” Emerging Infectious Diseases 5(1):159-63. doi: DOI 10.3201/eid0501.990121.

Greenbaum, S. D. 2006. "Introduction to working with Animal Assisted Crisis Response animal handler teams.” International Journal Of Emergency Mental Health 8(1): 49-63.

Han, Mei Mei, and Gonzalo Tapia Rico. 2019. “The "Pet Effect” in Cancer Patients: Risks and Benefits of Human-Pet Interaction." Critical Reviews in Oncology Hematology 143:56-61. doi: 10.1016/j.critrevonc.2019.08.004.

Humane Society 2020. “Coronavirus (COVID-19) FAQ”. Retrieved on March 31, 2020. (https://www.humanesociety.org/resources/coronavirus-covid-19-faq)

Idexx. 2020, “Idexx Sars-Cov-2 (Covid-19) Realpcr Test”. Retrieved Mar 30, 2020 (https://www.idexx.com/en/veterinary/reference-laboratories/idexx-sars-cov2-covid-19-realpcr-test/).

Independent 2020. “More dogs in shelters will be euthanized during coronavirus outbreak, warns animal rights group” Retrieved on March 26th, 2020 (https://www. independent.co.uk/news/world/americas/coronavirus-dogs-euthanized-animal-shelters-adopt-help-donate-a9410141.html)

International Association for Animal Hospice and Palliative Care 2020. “COVID-19 Practice Guidelienes”. Retrieved on March 31, 2020 (http://www.iaahpc.org)

Jones, Melanie G., Simon M. Rice, and Susan M. Cotton 2019 Incorporating animal-assisted therapy in mental health treatments for adolescents: A systematic review of canine assisted psychotherapy. PLoS ONE 14(1):e0210761.https://doi. 
org/10.1371/ journal.pone.0210761

Localsyr 2020. "Animal shelters, rescues see increase in adoption and foster applications amid COVID-19 pandemic”. Retrieved on March 30, 2020 (https://www.localsyr.com/health/coronavirus/animal-shelters-rescues-see-increase-in-adoption-foster-applications-amid-covid-19-pandemic/).

Lowrey, Sarah 2020. "Helping your dog survive during a quarantine”. Retrieved March 20, 2020 (https://www.nytimes.com/2020/03/17/smarter-living/dog-pets-quarantine-coronavirus-tips.html).

Maddie's Fund 2020. “COVID-19 and Emergency Foster Care Resources” Retrieved on March 31, 2020. (https://www.maddiesfund.org/covid-19-emergency-foster-care-resources.htm?_ga=2.168661990.617640744.158498495724388742.1584984957).

McMarlin, Shirley 2020. “Verterinarians, pet owners forced to adjust during COVID-19 outbreak". Retrieved on March 31, 2020. (https://triblive.com/lifestyles/ more-lifestyles/covid-19-unlikely-to-pass-between-pets-and-humans-vetssay/ )

Metro 2020. “Coronavirus UK lockdown: Can you walk your dog or your neighbours' dog for them?” Retrieved on March 26th, 2020. (https://metro.co.uk/2020/03/24/ coronavirus-uk-lockdown-can-walk-dog-neighbours-dog-12449059/)

Millán-Oñate, José, Alfonso J Rodriguez-Morales, German Camacho-Moreno, Henry Mendoza-Ramírez, Iván Arturo Rodríguez-Sabogal and Carlos Álvarez-Moreno. 2020. "A New Emerging Zoonotic Virus of Concern: The 2019 Novel Coronavirus (Covid-19).” Infectio 24(3).

Mondelli F., Prato-Previde E., Verga M., Levi D., Magistrelli S., Valsecchi P. 2004. "The Bond That Never Developed: Adoption and Relinquishment of Dogs in a Rescue Shelter”. Journal Of Applied Animal Welfare Science 7:253-66. 10.1207/ s15327604jaws0704_3.

My Dog is My Home. 2020. “Co-Sheltering”. Retrieved on March 31, 2020 (https:// www.mydogismyhome.org/)

National Geographic 2020. "Fake animal news abounds on social media as coronavirus upends life” Retrieved on March 31, 2020 (https://www.nationalgeographic.com/animals/2020/03/coronavirus-pandemic-fake-animal-viral-social-media-posts/)

NY Post 2020. “Chinese resident on coronavirus lockdown 'walks' dog from balcony with leash” Retrieved March 26, 2020 (https://nypost.com/2020/02/19/chineseresident-on-coronavirus-lockdown-walks-dog-from-first-floor-balcony-withleash/)

NY Times 2020. "Stuck at Home, Americans Turn to Foster Pets for Companionship” Retrieved on March 26, 2020 (https://www.nytimes.com/2020/03/19/us/coronavirus-foster-pets.html)

Oliver, Laura 2020. "It could take three years for the US economy to recover from COVID-19”. World Economic Forum March 30, 2020. (https://www.weforum.org/ agenda/2020/03/economic-impact-covid-19/)

Otranto, D., F. Dantas-Torres, A. D. Mihalca, R. J. Traub, M. Lappin and G. Baneth. 2017. 
"Zoonotic Parasites of Sheltered and Stray Dogs in the Era of the Global Economic and Political Crisis." Trends in Parasitology 33(10):813-25. doi: 10.1016/j. pt.2017.05.013.

Podlaskie 2020. Dzikie zwierzęta wychodzą do miast. Zastąpiły ludzi.” Retrieved March 26,2020

Prenger K. 2018. “War Zone Zoo: The Berlin Zoo and World War 2". Independently published.

Psychology Today 2020. “COVID-19 and Planning for Your Pet”. Retrieved on March 31, 2020 (https://www.psychologytoday.com/us/blog/fellow-creatures/202003/ covid-19-and-planning-your-pet)

Roca, R. Y. and R. J. McCarthy. 2019. "Impact of Telemedicine on the Traditional Veterinarian-Client-Patient Relationship.” Topics in Companion Animal Medicine 37. doi: UNSP 100359

Scherk, Margie A., Richard B. Ford, Rosalind M. Gaskell, Katrin Hartmann, Kate F. Hurley, Michael R. Lappin, Julie K. Levy, Susan E. Little, Shila K. Nordone, and Andrew H. Sparkes. 2013. “2013 Aafp Feline Vaccination Advisory Panel Report.” Journal of Feline Medicine and Surgery 15(9):785-808. doi: 10.1177/1098612X13500429.

Sentient 2020. "Other Animals Are Not Humans' Sacrificial Fall Guys". Retrieved on March 31, 2020. (https://sentientmedia.org/other-animals-are-not-humans-sacrificial-fall-guys/?fbclid=IwAR3GFoaA96blX3FwYnZU3ZuZMvaAoZL-FxduiPv5RAmHH3bgnR-iByWG_TE)

Specktor, Brandon 2020. "What is flattening the curve and will it work? Live Science". Retrieved on March 26, 2020 (https://www.livescience.com/coronavirus-flatten-the-curve.html)

The Local 2020. "How dogs have become hot property during Spain's coronavirus lockdow” Retrieved on March 26, 2020. (https://www.thelocal.es/20200319/whyeveryone-in-spain-wishes-they-had-a-dog-during-the-coronavirus-lockdown)

Tilocca, Bruno, Alessio Soggiu, Vincenzo Musella, Domenico Britti, Maurizio Sanguinetti, Andrea Urbani, and Paola Roncada. 2020. "Molecular basis of COVID-19 relationships in different species: a one health perspective”. Microbes Infect. 2020 Mar 17. pii: S1286-4579(20)30048-4. doi:10.1016/j.micinf.2020.03.002.

Today 2020. Tonka the therapy dog brings joy to nursing home during coronavirus quarantine". Retrieved on March 31, 2020 (https://www.today.com/pets/tonka-therapy-dog-brings-joy-nursing-home-during-coronavirus-quarantine-t176350)

TurnTo23 3030. "Video Of A Drone 'walking” A Dog During The Coronavirus Lockdown Goes Viral” Retrieved on March 26, 2020 (https://www.turnto23.com/video-ofdrone-walking-dog-during-coronavirus-lockdown-goes-viral/)

Underwood, Wendy and Raymond Anthony. 2013. "AVMA Guidelines for the Euthanasia of Animals: 2020 Edition”. Retrieved on March 30, 2020 (https://www.avma. org/sites/default/files/2020-01/2020-Euthanasia-Final-1-17-20.pdf)

Vice 2020. "People in Sydney Are Asking Vets to Euthanise Their Dogs So They Don't Get Coronavirus” Retrieved on March 26th, 2020 (https://www.vice.com/en_au/ article/wxe78x/people-in-sydney-ask-vets-to-euthanise-pets-so-they-dontget-coronavirus) 
Vogt, Amy Hoyumpa, Ilona Rodan, Marcus Brown, Scott Brown, CA Tony Buffington, MJ LaRue Forman, Jacqui Neilson, and Andrew Sparkes. 2010. "Feline Life Stage Guidelines.” Journal of Feline Medicine and Surgery 12(1):43-54. doi: 10.1016/j. jfms.2009.12.006.

Wood, L., Martin, K., Christian, H., Nathan, A., Lauritsen, C., Houghton, S., Kawachi, I. and McCune, S., 2015. The pet factor-companion animals as a conduit for getting to know people, friendship formation and social support. PloS one, 10(4)

World Health Organization 2020. "Rolling updates on coronavirus disease" Retrieved n March 31, 2020 (https://www.who.int/emergencies/diseases/novel-coronavirus-2019/events-as-they-happen)

Wright, Jennifer G., Sherry Jung, Robert C. Holman, Nina N. Marano, and Jennifer H. McQuiston. 2008. "Infection Control Practices and Zoonotic Disease Risks among Veterinarians in the United States." Journal of the American Veterinary Medical Association 232(12):1863-72. doi: DOI 10.2460/javma.232.12.1863.

YouTube 2016. "Funny Parrot (When u are alone at home)" Retrieved on March 31, 2020 (https://www.youtube.com/watch?v=JNxh3r0346Y)

Zeitlin, Matthew. 2020. "Hurricane Katrina inspired a national pet evacuation policy. The plan could save human lives, too.” Retrieved on March 31, 2020 (https:// www.vox.com/the-highlight/2019/11/8/20950253/wildfires-hurricane-katrina-pet-evacuation)

\section{BIOGRAPHICAL NOTE}

Kathleen J. Farkas, Ph.D. LISW-Supv. is an Associate Professor of Social Work at the Jack, Joseph and Morton Mandel School of Applied Social Sciences, Case Western Reserve University, Cleveland, Ohio USA. She has extensive clinical and research experience in the areas of mental health and addictions assessment and treatment. Dr. Farkas a long time interest in substance use issues among older adults and women and her work has focused on addictions and mental health issues among those incarcerated in jails and prisons. Recently she has been involved in research, teaching and service efforts using animal assisted interventions in mental health and addictions. She is the chairperson of the Mandel School's direct practice faculty as well as the specialization faculty for substance use disorders and recovery.

Aviva Vincent, $\mathrm{PhD}$ is a graduate of Case Western Reserve University, Mandel School of Social Welfare in veterinary social work. Her research focuses on the biological impact that animals have on children, specifically in the reduction on fear and anxiety in stressful situations. Methodologically, her research interest is the integration of salivary analyte measures in social science research. Her background in veterinary social work informs her practice as the Director of Program Quality at Fieldstone Farm Therapeutic Riding Center in Chagrin Falls, Ohio. She is an instructor of macro course-work at Case Western Reserve University, and teaches in the University of Tennessee in the Veterinary Social Work Certificate Program. Aviva is founder and co-chair of the human-animal interactions workgroup with National Association of Social Workers, Ohio chapter.

Zenithson Ng is a clinical associate professor at the University of Tennessee. He earned his undergraduate degree in animal science from Rutgers University and his veterinary degree from Cornell Univer- 
sity; then completed a small animal rotating internship at the ASPCA in NYC, followed by an American Board of Veterinary Practitioners (ABVP) canine/feline residency combined with a master's degree in human-animal bond studies at Virginia Tech. His research and teaching interests span all aspects of the human-animal bond including the effect of human-animal interaction on both humans and animals, the veterinary-client relationship, and stress reduction in both veterinary and animal-assisted intervention settings.

Hanna Mamzer is professor of sociology at the Adam Mickiewicz University in Poznań, Poland.

OPEN ACCESS: This article is distributed under the terms of the Creative Commons Attribution Non-commercial License (CC BY-NC 4.0) which permits any non-commercial use, and reproduction in any medium, provided the original author(s) and source are credited.

ARTICLE HISTORY: Received 2020-03-30 / Accepted 2020-04-10 
